Western University Scholarship@Western

1982

\title{
Inventories and Price Inflexibility
}

Seiichi Kawasaki

John McMillan

Klaus F. Zimmermann

Follow this and additional works at: https://ir.lib.uwo.ca/economicsresrpt Part of the Economics Commons

Citation of this paper:

Kawasaki, Seiichi, John McMillan, Klaus F. Zimmermann. "Inventories and Price Inflexibility." Department of Economics Research Reports, 8201. London, ON: Department of Economics, University of Western Ontario (1982). 
ISSN : $\quad 0318-725 \mathrm{X}$

ISBN : $\quad 0-7714-0316-X$

RESEARCH REPORT 8201

INVENTORIES AND PRICE INFLEXIBILITY

by

Seiichi Kawasaki

John McMillan

Klaus F. Zimmermann

\section{ABSTRACT}

A firm maximizing expected discounted profits, taking account of the actions of its competitors, and choosing price and output before (stochastic) demand is known, is shown to respond to a change in demand by changing output alone if the demand change is transitory, but by changing both price and output if the demand change is permanent. This proposition is shown to be consistent with German data. Since the data are qualitative, the empirical analysis uses the multivariate conditional logit model; the empirical results are summarized by gamma coefficients.

Revised January 1982

Correspondence to: J. McMillan Department of Economics University of Western Ontario London, Ontario N6A 5C2 Canada

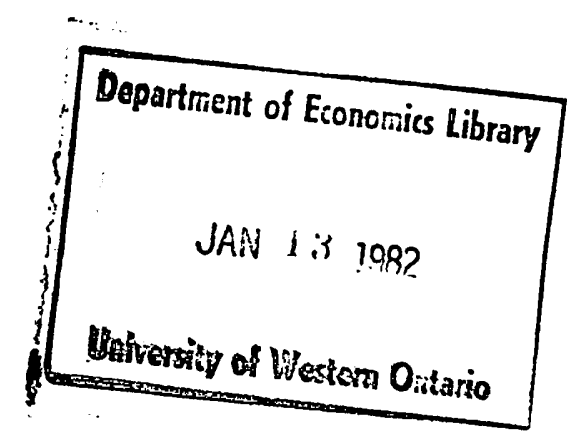




\section{INTRODUCTION}

Economic theorists have been concerned recently with making the theory of the behavior of firms, as developed by Cournot and his successors, better able to describe the behavior of actual firms by adding to the theory such features of reality as product differentiation, dynamics, and uncertainty. ${ }^{2}$ In this area of research lies the stochastic-game model of firms' price, output, and inventory policies due to Kirman and sobel [12]. 3 This paper firstly develops a testable corollary of the Kirman-Sobel theorem, and secondly confronts the corollary with data from German industry. The proposition to be derived is that a firm reacts differently to a demand change depending on whether the firm perceives the change to be permanent or transitory: the firm tends to change both price and output in response to a permanent demand change, but changes only output in response to a temporary demand change. This hypothesis is shown, with some qualifications, to be supported by the data.

Many macroeconomic models are based on the assumption that prices are less flexible than quantities (see Barro and Grossman [1] and Malinvaud [14]). This assumption has obtained some empirical support (see for example Kawasaki, McMillan, and Zimmermann [10]) but the reason why prices should be sticky has been left unexplained. The model of dynamic profit maximization under uncertainty and imperfect competition discussed in this paper provides a possible microeconomic rationale for this macroeconomic assumption.

Section 2 presents an exposition of the Kirman-Sobel model and a statement of its testable implications. An empirical test is carried out in Section 3. Section 4 summarizes the paper. 


\section{INVENTORY STRATEGY}

Kirman and Sobel [12] described an industry whose firms produce differentiated commodities. (The assumption of product differentiation is needed to rule out the discontinuities due to sudden switches of customers from one firm to another as described by Bertrand [2].) There are N firms in the industry; $N$ may be, but need not be, a large number. The firms need not be of equal size. Each firm's sales depend not only on the price it charges, but also on the prices of the other firms. In addition, each firm's demand function fluctuates randomly. Let $d_{j}^{t}$ represent the demand function facing firm $j$ in period $t: d_{j}^{t}$ is a random variable whose distribution depends on the prices charged by all firms in period $t$ but is independent of the values of any of the variables in the past. At the beginning of period $t$, and before its demand in that period is known, each firm makes both its pricing and production decisions for that period: let $q_{j}^{t}$ and $p_{j}^{t}$ denote the output and price of firm $j$ in period $t$. Because both price and output are decided in advance of each period's demand, there will usually be a stock of inventory (or unfilled orders) to carry over to the next period. Let $x_{j}^{t}$ denote the inventory firm $j$ has on hand at the start of period $t . x_{j}^{t}$ may be positive or negative; if negative it represents unfilled orders. (The model also covers the case in which sales are lost in any period in which demand exceeds supply.) Define $y_{j}^{t}$ by

$$
y_{j}^{t} \equiv x_{j}^{t}+q_{j}^{t}
$$

$y_{j}^{t}$, which will be referred to as firm $j$ 's stock, is the total quantity of goods available to satisfy the demand for firm $j$ 's product during period $t$. Inventories are carried over from one period to the next, so that

$$
x_{j}^{t+1}=y_{j}^{t}-d_{j}^{t}
$$


The firm produces under constant returns to scale, and as well faces inventory holding costs and costs of back-ordering. Its objective is to maximize the expected present value of its stream of future profits over an infinite time horizon.

Kirman and Sobel modelled the firms' interdependencies as a stochastic game and proved the following theorem. For each firm $f$ there is a price $\bar{p}_{j}$ and a stock $\bar{y}_{j}$ such that (provided $x_{j}^{1} \leq \bar{y}_{j}$ ) there exists a dynamic equilibrium with the property that $p_{j}^{t}=\bar{p}_{j}$ and $y_{j}^{t}=\bar{y}_{j}$ for all $t=1,2, \ldots$.

The Kirman-Sobel result can be understood as follows. (For a precise statement of the underlying assumptions and a formal proof, see Kirman and Sobel [12]. For a proof of existence of equilibrium, see Sobe1 [22].) Firm j's profit in period $t$ is

$$
\pi_{j}^{t}=p_{j}^{t} d_{j}^{t}-I_{j}\left(x_{j}^{t+1}\right)-c_{j} q_{j}^{t}
$$

where $I_{j}(\cdot)$ represents costs associated with holding inventories and unfilled orders and $c_{j}$ is the (constant) marginal cost of production. Using (1) and (2), (3) can be rewritten in terms of price, demands, and stocks only:

$$
\pi_{j}^{t}=p_{j}^{t} d_{j}^{t}-I_{j}\left(y_{j}^{t}-d_{j}^{t}\right)-c_{j} \cdot\left(y_{j}^{t}-\left(y_{j}^{t-1}-d_{j}^{t-1}\right)\right)
$$

The firm seeks to maximize $E\left[\Sigma_{t=1}^{\infty} \alpha_{j}^{t-1} \pi_{j}^{t}\right]$ where $\alpha_{j}$ is firm j's discount parameter and $\mathrm{E}$ denotes the expectation operator. This is, in the terminology of Friedman [4, Ch. 9], a game with time dependence: profit in any period depends on the value of past variables (namely $y_{j}^{t-1}-d_{j}^{t-1}$ ) as well as present variables. It is, however, equivalent to a simpler game, lacking time dependence. The term $y_{j}^{t-1}-d_{j}^{t-1}$ represents the amount of inventories carried over to period $t$. The value of inventories now is that they reduce the cost of production incurred next period; thus the 
firm's valuation now of one unit of the commodity in inventory is $\alpha_{j} c_{j}$. (Note that this step crucially relies on the assumption of constant returns to scale in production; without constant returns to scale, the value of inventories cannot be so defined. ${ }^{4}$ ) It follows that the game of maximizing the expected present value of the terms $\pi_{j}^{t}$ is equivalent to the game of maximizing the expected present value of the terms $\xi_{j}^{t}$, where $\xi_{j}^{t}$ is defined by

$$
\xi_{j}^{t-1}=p_{j}^{t-1} d_{j}^{t-1}-I_{j}\left(y_{j}^{t-1}-d_{j}^{t-1}\right)-c_{j} y_{j}^{t-1}+\alpha_{j} c_{j} \cdot\left(y_{j}^{t-1}-d_{j}^{t-1}\right)
$$

This transformed game lacks time dependence. Finally, taking expectations (remembering that $d_{j}^{t}$ is a random variable whose distribution depends on all the prices), write $E\left[\xi_{j}^{t}\right]=G_{j}\left(p^{t}, y^{t}\right)$, where $p^{t}=\left(p_{1}^{t}, \ldots, p_{N}^{t}\right), y^{t}=\left(y_{1}^{t}, \ldots y_{N}^{t}\right)$. The problem has been reduced to that of finding a solution of the repeated game whose payoff function for firm $j$ in each period is $G_{j}$. Each period's profit depends only on the prices $p^{t}$ and stocks $y^{t}$ for that period (and not directly on outputs $q^{t}$ or inventories $x^{t}$ ). It is well known that one of the equilibria of a time-independent repeated game is simply the repeated playing of a single-period-game (Cournot-Nash) equilibrium. Consider the static game in which firm j's objective is to choose $p_{j}$ and $y_{j}$ to maximize $G_{j}(p, y)$; denote the Cournot-Nash equilibrium of such a game by $\bar{p}, \bar{y}$, where $\bar{p}=\left(\bar{p}_{1}, \ldots, \bar{p}_{N}\right)$ and $\bar{y}=\left(\bar{y}_{1}, \ldots, \bar{y}_{N}\right)$. Then a solution of the repeated game whose objective is to maximize $\Sigma_{t=1}^{\infty} \alpha_{j}^{t-1} G_{j}\left(p^{t}, y^{t}\right)$ involves firm $j$ repeatedly playing $\bar{p}_{j}, \bar{y}_{j}$; hence the Kirman-Sobel theorem.

Because of the unpredictability of demand in each period, inventories in this model serve as buffer stocks. Because it is assumed that a firm cannot instantaneously adjust price or output, the immediate effect of a change in demand is a change in the level of inventories. The model 
predicts that this inventory change is followed in the next period by a change in the rate of production. The meaning of the Kirman-Sobel theorem is that, provided the initial level of inventories is not too high, the firm operates so as to maintain a constant target stock $\bar{y}_{j}$. The equilibrium strategy prescribes that firm $\mathrm{j}$ responds to an increase (decrease) in its demand in period $t$ by an equally-sized increase (decrease) in output in period $t+1$. (Because from (1) $q_{j}^{t+1}=y_{j}^{t+1}-x_{j}^{t+1}=y_{j}^{t+1}-\left(y_{j}^{t}-d_{j}^{t}\right)$ from (2). Putting $y_{j}^{t}=y_{j}^{t+1}=\bar{y}_{j}, q_{j}^{t+1}=d_{j}^{t}$ so that $q_{j}^{t+1}-q_{j}^{t}=d_{j}^{t}-d_{j}^{t-1}$ )

The Kirman-Sobel theorem has an implication apparently not noticed before. The result depends upon the assumption that the demand function fluctuates randomly around a given mean. The firm counteracts these fluctuations by changing its output while leaving its price unchanged. If, in addition to these random fluctuations, the mean of the demand function were to shift, the parameters of the game would be different. A new equilibrium would emerge, with each firm having both a new target stock and, perhaps, a new price. ${ }^{5}$ Thus the theorem implies the following testable hypotheses :

(i) A firm will not change the price it charges if it perceives the demand change to be transitory; it may however change its price in response to a permanent change in the previous period's demand.

(ii) A firm will change its output in response to any change, temporary or permanent, in the previous period's demand.

Kirman and sobel considered only one type of dynamic equilibrium, the analog of the repeated cournot equilibrium. In dynamic oligopoly models there often exist other, implicitly collusive, equilibria, generated 
by the firms following non-trivial reaction functions. ${ }^{6}$ one might conjecture that a similar possibility exists here. Suppose firms, in their price decisions, react to their rivals' prices and, in their output decisions, simply follow demand changes. That oligopolists actually achieve implicit collusion by such a policy has been suggested by the empirical observations of Scherer [20, pp. 193-197] and by the oligopoly experiments of Friedman and Hoggatt [5]. If, in this way, price is the variable chosen to enforce implicitly collusive outcomes, then the conclusion stated in the previous paragraph still holds: prices will tend to be stable in the face of temporary demand changes. However, contrary to what Scherer [20, p. 194] suggested, price stability is not in itself evidence that implicit collusion is occurring because, according to the model described above, prices will also tend to be stable at a Cournot-type equilibrium.

Propositions similar to (i) and (ii) have been stated before in the industrial organization 1iterature. ${ }^{7}$ The contribution of the foregoing analysis is to show that such behavior is consistent with neoclassical economic theory by showing it is a consequence of the profit-maximizing decisions of firms.

Note that, in this model, no assumptions about the relative ease of changing price as compared with changing output are imposed. Both types of change are assumed to be costless. Moreover, it is assumed to take the firm the same length of time (one period) to change output as to change price. In these two respects the model is, in its assumptions, neutral with respect to price flexibility versus output flexibility. Differences between price and output flexibility arise solely from the firms' choices. 


\section{ESTIMATION}

We use business-survey data collected by the Ifo-Institut fuer Wirtschaftsforschung of Munich. The data set consists of two years' monthly observations in various branches of industry from 1977 to 1978. The data, which are qualitative, contain detailed micro-information on each firm including its expectations. We used the following four variables :

(i) $P_{t}$, the change in price from the previous month to the current month;

(ii) $Q_{t}$, the change in production level from the previous month;

(iii) $D_{t}$, the change in incoming orders from the previous month, which we use to represent the short-run change in demand;

(iv) $G_{t}^{*}$, the expected change in the business conditions for the product of the firm over the next six-month period, which we use as a proxy for the change in long-run demand. $^{8}$

A11 the above four variables have three categories: namely, increase, no change, and decrease.

According to the theoretical hypotheses (i) and (ii) set up in Section 2, the dependent variables in our statistical models are the change in price $\left(P_{t}\right)$ and the change in production activity $\left(Q_{t}\right)$, while the independent variable is the change in short-run demand with a onemonth lag $\left(D_{t-1}\right) \cdot 9$ One possible statistical specification for our hypotheses would be two separate univariate conditional logit models for price and production. However, there are probably some omitted 
variables, such as cost changes, which affect both price and production. In order to capture the effect of these omitted variables, we combine the two logit models into one joint logit model which allows for interdependence between the two dependent variables (price and production changes) as well as dependence of these variables on perceived demand. This class of logit model, the multivariate conditional logit model, was developed by Nerlove and Press [18, 19] and applied to Ifo data by Koenig, Nerlove and Oudiz [13] and Nerlove [17]. This approach also enables us to test statistically the difference between the magnitude of price response and that of production response, which is required in order to evaluate the theoretical hypotheses of Section 2 . If we estimated the models separately, this statistical comparison would be very difficult. The specification of the model is given by (using $\operatorname{Pr}$ to denote probability):

$$
\begin{aligned}
& \operatorname{Pr}\left(P_{t}=i, Q_{t}=j \mid D_{t-1}=k\right)=\frac{\exp \left(S\left(i_{2} \mid k\right)\right)}{\sum_{i^{\prime}=1} \sum_{j^{\prime}=1}^{J} \exp \left(S\left(i^{\prime}, j^{\prime} \mid k\right)\right)}, \\
& S(i, j \mid k)=\sum_{i^{\prime}=1}^{I} \alpha_{i^{\prime}}^{P} \cdot d_{i^{\prime}}(i)+\sum_{j^{\prime}=1}^{J} \alpha_{j^{\prime}}^{Q} \cdot d_{j^{\prime}}(j) \\
& +\sum_{i^{\prime}=1}^{I} \sum_{j^{\prime}=1} \beta_{i^{\prime} j^{\prime}}^{P Q} \cdot d_{i^{\prime}}(i) \cdot d_{j^{\prime}}(j) \\
& +\sum_{i^{\prime}=1}^{I} \sum_{k^{\prime}=1}^{K} \beta_{i^{\prime} k^{\prime}}^{P D} \cdot d_{i^{\prime}}(i) \cdot d_{k^{\prime}}(k) \\
& +\sum_{j} \sum_{j^{\prime}=1} \beta_{k^{\prime}=1}^{Q D} \beta^{\prime} k^{\prime} \cdot d_{j^{\prime}}(j) \cdot d_{k^{\prime}}(k),
\end{aligned}
$$

where $I, J$ and $K$ are the numbers of categories of $P_{t}, Q_{t}$, and $D_{t-1}$ respectively, $d_{i}(j)$ is a dummy variable taking value 1 when $i=j$ and value 0 otherwise, and the following normalizing restrictions are imposed on the parameters:

$$
\sum_{i=1}^{I} \alpha_{i}=0, \quad \sum_{i=1}^{I} \beta_{i j}=\sum_{j=1}^{J} \beta_{i j}=0 \text { for all } i \text { and } j \text {. }
$$


The $s(1, j \mid k)$ in the model can be interpreted as the utility that the firm receives when it makes the decision that $P_{t}=i$ and $Q_{t}=j$ when $D_{t-1}=k \cdot{ }^{10}$ The parameters, $\alpha$ and $\beta$, may be interpreted in the same way as in the usual regression analysis with dummy variables and interaction terms. In particular the parameters $\beta^{P Q}$ represent the correlation between price change and production change due to some omitted variables. We do not interpret $\beta^{P Q}$ as representing any simultaneous feed-back relationship between the endogenous variables. ${ }^{11}$ If the $\beta^{P Q_{1}}$ s are all zero, the system (6) is just the product of two univariate logit models of price and production. It should be also noted that our model, in contrast to the usual regression analysis, is concerned with the frequency or probability of responses instead of the magnitudes of responses.

A set of $3 \times 3$ estimated contingency tables, each showing the ceteris paribus interaction between an exogenous variable and an endogenous variable, can be calculated from the parameter estimates in (6). For each interaction there are nine estimated probabilities and a nine-by-nine asymptotic covariance matrix. In order to facilitate the interpretation of each interaction, we summarize the information contained in the estimated contingency tables by a single association measure, the gamma coefficient (originally developed by Goodman and Kruskal [6], and applied to the logit model by Kawasaki [9] and Kawasaki and Zimmermann [11]). Suppose we have two ordinal categorical variables with indexes $i$ and $j$. Choose any two observations $\left(i_{1}, j_{1}\right)$ and $\left(i_{2}, j_{2}\right)$. at random from a population with replacement. The pair of observations is said to be positively associated if $i_{1}<i_{2}$ and $j_{1}<j_{2}$ or if $i_{1}>i_{2}$ and $j_{1}>j_{2}$, and negatively associated if $i_{1}<i_{2}$ and $j_{1}>j_{2}$ or if $i_{1}>i_{2}$ and $j_{1}<j_{2}$. Given a set of cell probabilities, it is straightforward to calculate the probability of obtaining positively-associated pairs $\left(\pi_{+}\right)$and the probability of 
obtaining negatively-associated pairs $\left(\pi_{-}\right)$. The gamma coefficient measures how much more probable it is to obtain positively-associated pairs than negatively-associated pairs given that there are no tied observations (that is, $i_{1} \neq i_{2}$ and $j_{1} \neq j_{2}$ ):

$$
\gamma \equiv \frac{\pi_{+}-\pi_{-}}{\pi_{+}+\pi_{-}} .
$$

The gamma coefficient is analogous to the usual correlation coefficient in that it takes the value plus one if the two variables are positively associated, zero if they are independent, and minus one if they are negatively associated.

The data set contains 95,020 observations for each variable. As suggested by the propositions derived in the analysis of Section 2, two distinctive cases were considered. Firstly, when the long-run expectation for demand $\left(G_{t-1}^{*}\right)$ remains unchanged, the hypothesis predicts that the firm responds to the change in short-run demand $\left(D_{t-1}\right)$ not by price $\left(P_{t}\right)$ but by output $\left(Q_{t}\right)$. On the other hand, when a change in long-run demand is expected and the short-run change in demand is consistent with the longrun change, the firm, according to the theory, should adjust both price and output. Thus we separated the data in two subsamples, with 63,763 observations in the case where $G *$ equals "no change" and 16,609 observations in the case where $G *=D$ and $D$ equals "increase" or "decrease", neglecting 14,648 observations. For both subsamples we estimated model (6) for all available time points, several industry groups and a total sample pooled over all periods and all industries. ${ }^{12}$ Due to the problem of sampling zeros in the contingency-table analys is ${ }^{13}$ we were not able to estimate the model in several cases.

Table I lists the results for individual industries, pooled over time. The gamma coefficient for the bivariate interactions is used as a 
summarizing statistic. Table I also reports the likelihood-ratio chi-square value (LRT), which is defined as $-2[\log L V(M)-\log \operatorname{LV}(I)]$, where $\operatorname{LV}(M)$ is the value of the maximized log-likelihood function of the model and IV(I) the value of the maximized log-likelihood function of the null-hypothesls model, that is the model which does not contain the $\beta^{P D}$ and $\beta^{Q D}$ parameters. The difference between gamma coefficients, DIF $=\gamma(P D)-\gamma(Q D)$, is computed. The time series and the total sample results are not reported, because they yield little extra information.

Several aspects of the empirical implications of the Kirman-Sobel model are supported by the data. From the chi-square tests (see the first and the fifth columns of the table) we can, for all industries, clearly reject the null hypothesis that neither price nor output responds to a demand change in the previous month. This justifies our modelling, in equation (6), the firms as responding with price and/or output changes to the previous month's demand fluctuations. According to the gammacoefficient estimates, a demand increase (decrease) is followed by an output increase (decrease) and either a price increase (decrease) or no price change. The separation of the data shows that firms react differently depending on whether demand changes are perceived as being transitory or permanent: in all cases the price and quantity reactions are much more marked in the permanent case (see the sixth and seventh columns of the table) than in the transitory case (see the second and third columns of the table). Moreover, in six cases out of eleven, transitory changes in demand have no significant effects on prices, whereas, in ten cases out of eleven, permanent changes in demand have significant effects on prices. Outputs react to both temporary and permanent demand changes; only in one (transitory) case is there a non-significant output interaction. As a 
consequence, quantity reactions are much more marked than price reactions in the case of temporary demand changes: see the difference-test statistics (the fourth column of the table). Thus, while results vary from industry to industry, for most industries there is a significant relationship between transitory demand changes and output changes, an insignificant or weak relationship between transitory demand changes and price changes, and significant relationships between permanent demand changes and both output and price changes.

In contrast to Scherer's suggestion [20, p. 194] that prices will be stable in oligopolistic industries and flexible in competitive industries, the model of Section 2 suggests that prices will be stable in the face of transitory demand changes regardless of market structure (because the model requires no assumptions about the number or relative size of firms). The empirical results appear to support the latter contention. The last column of the table reports for each industry the ten largest firms' sales as a percentage of total industry sales. There seems to be no relationship between price inflexibility and concentration (compare, for example, plastics and products with electrical equipment).

Some limitations of this empirical test should be noted. Firstly, G*, the expected change in business conditions over the succeeding six months, may not reflect perfectly long-run demand changes. The time horizon may be too short, or $G *$ may include as well other variables such as costs. ${ }^{14}$ Secondly, the theoretical results relied on the assumption of constant returns to scale; if a firm is not operating under approximately constant returns to scale in the relevant output range, there is no reason to expect it to behave as the theory predicts. Thirdly, the theory is expressed in terms of relative prices, while the data refer to absolute prices. The theoretical prediction is that the firm will not change its 
relative price in response to a transitory demand change. In an inflationary environment (in 1977, the German inflation rate in manufacturing industries was 2.7 percent and in 1978, 1.1 percent) a firm can change its absolute price without changing its relative price; this may explain why some of the measured price responses to transitory demand changes are significantly different from zero.

\section{CONCLUSION}

This paper presents a theoretical argument and empirical evidence supporting the proposition that firms tend to change both price and output in response to a permanent change in demand, but only output in response to a transitory change in demand. This may provide a partial explanation of the observed fact that prices are less flexible than quantities, a fact which has fundamental implications for macroeconomic modeling.

The paper gives an exposition of the Kirman-Sobel theorem [12] and shows as a corollary that a firm reacts differently to a demand change depending on whether the firm perceives the change to be permanent or transitory. Thus this reasonable-looking proposition is shown to be consistent with profit-maximizing behavior. The model demonstrates that, contrary to what has been claimed in the industrial organization literature, price stability is not in itself evidence of implicit collusion.

Based on this theoretical analysis, a multivariate conditional logit model is estimated using German data. For the industries for which estimates can be obtained, the empirical results are that transitory increases (decreases) in demand tend to be followed significantly by output 
increases (decreases) and insignificantly or infrequently by price changes; permanent demand increases (decreases) are followed significantly by both output increases (decreases) and price increases (decreases).

University of Mannheim,

University of Western Ontario, and

University of Mannheim 
REFERENCES

[1] Barro, R. J., and H. I. Grossman: Money, Employment and Inflation. Cambridge: Cambridge University Press, 1976.

[2] Bertrand, J.: Review of Recherches sur les Principes Mathématiques de 1a Theorie des Richesses, Journal des Savants (1883), 499508.

[3] Bishop, Y. M. M., S. E. Fienberg, and P. W. Holland: Discrete Multivariate Analysis: Theory and Practice. Cambridge, Mass.: MIT Press, 1975.

[4] Friedman, J. W.: Oligopoly and the Theory of Games. Amsterdam: North-Holland, 1976.

[5] Friedman, J. W., and A. C. Hoggatt: An Experiment in Noncooperative 01igopoly. Greenwich, Conn.: JAI Press, 1980.

[6] Goodman, L. A., and W. H. Kruska1: Measures of Association for Cross Classifications. New York: Springer-Verlag, 1971.

[7] Haberman, S. J.: The Analysis of Frequency Data. Chicago: University of Chicago Press, 1974.

[8] Heckman, J. J.: "Dumny Endogenous Variables in a Simultaneous Equation System," Econometrica, 46 (1978), 931-959.

[9] Kawasaki, S.: "Application of Loglinear Probability Models in Econometrics," Ph.D. thesis, Northwestern University, 1979.

[10] Kawasaki, S., J. McMillan, and K. F. Zimmermann: "Disequilibrium Dynamics: An Empirical Study," American Economic Review, forthcoming.

[11] Kawasaki, S., and K. F. Zimmermann: "Measuring Relationships in the Loglinear Model by Some Compact Measures of Association," Statistische Hefte, 22 (1981), 94-121. 
[12] Kirman, A. P., and M. J. Sobel: "Dynamic 01igopoly with Inventories," Econometrica, 42 (1974), 279-287.

[13] Koenig, H., M. Nerlove, and G. Oudiz: "On the Formation of Price Expectations: An Analysis of Business Test Data by Log-Linear Probability Models," European Economic Review, 16 (1981), 103-138.

[14] Malinvaud, E.: The Theory of Unemployment Reconsidered. London: Blackwe11, 1977.

[15] McFadden, D.: "Conditional Logit Analysis of Qualitative Choice Behavior," in Frontiers in Econometrics, ed. by P. Zarembka. New York: Academic Press, 1973.

[16] Mills, E. S.: Price, Output, and Inventory Policy. New York: Wiley, 1962.

[17] Nerlove, M.: "Expectations, Plans and Realizations: In Theory and Practice," Presidential Address to the Econometric Society, 1981 ; forthcoming in Econometrica.

[18] Nerlove, M., and S. J. Press: "Univariate and Multivariate Loglinear and Logistic Models," Rand Corporation, Report R-1306-EDA/NIH, 1973.

[19] : Multivariate Loglinear Probability Models for the Analysis of Qualitative Data," Discussion Paper No. 1, Center for Statistics and Probability, Northwestern University, 1976.

[20] Scherer, F. M.: Industrial Market Structure and Economic Performance. Chicago: Rand MaNally, 2nd ed., 1980.

[21] Shubik, M., with R. Levitan: Market Structure and Behavior. Cambridge, Mass.: Harvard University Press, 1980. 
[22] Sobel, M. J.: "Myopic Solutions of Markov Decision Processes and Stochastic Games," Operations Research, 29 (1981), forthcoming.

[23] Vogler, K. A.: "The Business Situation: On the Meaning of an Undetermined Survey Variable," in In Search of Economic Indicators. New York: Springer-Ver1ag, 1977.

[24] Weiss, L. W.: "Stigler, Kindah1, and Means on Administered Prices," American Economic Review, 67 (1977), 610-619. 
FOOTNOTES

$1_{\text {This }}$ research, done while McMillan was visiting the University of Mannheim, was supported in part by the Deutsche Forschungsgemeinschaft (Grant No. 219/13-2). We thank James Friedman, Peter Howitt, Heinz Koenig, Hans-Werner Sinn, and two referees for comments on an earlier draft.

${ }^{2}$ See especially Friedman [4] and Shubik and Levitan [21].

$3_{\text {Related models were developed by Mills }[16, \text { Chs. 6, } 7] \text { and }}$ Shubik and Levitan [21, Ch. 8].

${ }^{4}$ That assuming constant returns to scale facilitates the solution of such a problem was noted by Mills [16, pp. 109-110].

${ }^{5}$ As in the elementary monopoly model, an increase in demand may result in no price change or a decrease in price. For example, for the demand function $q_{j}^{t}=\delta_{j}\left(p^{t}\right) \cdot c+c^{t}$, where $c$ is a parameter and $\epsilon^{t}$ represents the random shock, it can be shown that an isoelastic shift in the demand function (a change in the value of the parameter c) causes no change in the equilibrium price.

${ }^{6}$ On implicitly collusive reaction-function equilibria in models where firms have only one decision variable and in which there is no uncertainty, see Friedman [4, Chs. 5, 8].

${ }^{7}$ See for example Weiss [24] for a weaker statement of statement of conclusions similar to these (weaker in that Weiss's reasoning suggests there will be sma11, but not zero, price changes in response to transitory demand changes: Weiss's argument is based on the elasticity of demand being lower in the short run than in the long run). 
${ }^{8}$ Although the precise meaning of this variable depends upon the judgment of the individual respondent, Vogler [22], based on a special survey, found that the demand situation in the long run is the main factor in the firms' assessments of this variable, but other factors such as costs and capacity utilization may also affect the assessments.

$9^{9}$ This assumes that the length of a period in the Kirman-Sobel model (the time it takes a firm to observe and respond to demand changes) is one month. The reason why more lagged variables are not used in the present study is that the inclusion of more variables makes the logit models less likely to be estimable due to empty cells in the contingency table.

${ }^{10}$ For a detailed study of the choice mechanism in the logit model, see McFadden [15].

${ }^{11}$ Some authors (for example, Heckman [8]) criticized the multivariate logit method for its lack of structural interpretation, and recommended the use of the simultaneous probit method. We use, nevertheless, the former method in this paper, because of the justification of the multivariate logit specification for our relatively simple economic model as given above, and because the logit model requires far less computation than does the probit method in this case.

${ }^{12}$ Pooling over time and/or over industry might cause one problem in estimation; error terms of the model may be correlated, while the likelihood function used here assumes statistical independence among the error terms. Thus the parameter estimates might be affected by this misspecification. Although these matters have been extensively studied in the case of quantitative variables, little is known as yet about the 
qualitative-variable case.

${ }^{13}$ See Bishop, Fienberg and Holland [3, pp. 400-433], Haberman [7, pp. 34-35, 395-404], Kawasaki [9, pp. 84-118], and Koenig, Nerlove and Oudiz [13].

${ }^{14}$ See Vogler [24]. The model of Section 2 suggests, however, that a cost change should generate a price change in a similar way to a permanent demand change. 
TABLE I

PARAMETER ESTIMATES ${ }^{a}$

\begin{tabular}{|c|c|c|c|c|c|c|c|c|}
\hline \multirow[b]{2}{*}{ Industry } & \multicolumn{4}{|c|}{$G^{*}=$ "no change" } & \multicolumn{3}{|c|}{$G^{*}=$ "change" $=D$} & \multirow[b]{2}{*}{ C } \\
\hline & $\begin{array}{c}\mathrm{N} \\
(\mathrm{LRT})\end{array}$ & $\gamma(\mathrm{PD})$ & $\gamma(Q D)$ & DIF & $\stackrel{\stackrel{N}{(L R T)}}{(x)}$ & $\gamma(\mathrm{PD})$ & $\gamma(Q D)$ & \\
\hline Stone and clay & $\begin{array}{l}1561 \\
(126.50)\end{array}$ & $\begin{array}{l}0.577 * \\
(4.38)\end{array}$ & $\begin{array}{l}0.427 * \\
(6.76)\end{array}$ & $\begin{array}{r}0.150 \\
(1.00)\end{array}$ & $\begin{array}{l}320 \\
(65.60)\end{array}$ & $\begin{array}{l}0.855^{*} \\
(8.38)\end{array}$ & $\begin{array}{l}0.700 * \\
(8.18)\end{array}$ & 17.8 \\
\hline $\begin{array}{l}\text { Non-ferrous } \\
\text { metals }\end{array}$ & $\begin{array}{l}907 \\
(68.26)\end{array}$ & $\begin{array}{l}0.301 * \\
(3.07)\end{array}$ & $\begin{array}{c}0.114 \\
(1.39)\end{array}$ & $\begin{array}{c}0.187 \\
(1.44)\end{array}$ & $\begin{array}{l}396 \\
(59.80)\end{array}$ & $\begin{array}{l}0.579 * \\
(2.40)\end{array}$ & $\begin{array}{c}0.763 * \\
(11.82)\end{array}$ & 49.3 \\
\hline Chemicals & $\begin{array}{l}1262 \\
(133.94)\end{array}$ & $\begin{array}{l}0.248 * \\
(2.49)\end{array}$ & $\begin{array}{l}0.297 * \\
(4.57)\end{array}$ & $\begin{array}{l}-0.050 \\
(-0.39)\end{array}$ & $\begin{array}{l}155 \\
(28.15)\end{array}$ & $\begin{array}{l}0.717 * \\
(4.33)\end{array}$ & $\begin{array}{l}0.530 * \\
(4.30)\end{array}$ & 47.3 \\
\hline Machinery & $\begin{array}{l}9088 \\
(310.25)\end{array}$ & $\begin{array}{l}0.177 * \\
(2.89)\end{array}$ & $\begin{array}{c}0.298 * \\
(11.36)\end{array}$ & $\begin{array}{l}-0.121 \\
(-1.79)\end{array}$ & $\begin{array}{l}2790 \\
(395.78)\end{array}$ & $\begin{array}{l}0.512 * \\
(3.88)\end{array}$ & $\begin{array}{l}0.824 * \\
(34.94)\end{array}$ & 17.5 \\
\hline $\begin{array}{l}\text { Steel and non- } \\
\text { ferrous metal } \\
\text { mill products }\end{array}$ & $\begin{array}{l}1066 \\
(36.69)\end{array}$ & $\begin{array}{l}-0.104 \\
(-0.86)\end{array}$ & $\begin{array}{r}0.380 * \\
(5.209)\end{array}$ & $\begin{array}{c}-0.484 * \\
(-3.239)\end{array}$ & $\begin{array}{l}515 \\
(49.44)\end{array}$ & $\begin{array}{l}0.461 * \\
(1.94)\end{array}$ & $\begin{array}{l}0.758 * \\
(9.57)\end{array}$ & 40.6 \\
\hline $\begin{array}{l}\text { Electrical } \\
\text { equipment }\end{array}$ & $\begin{array}{l}6442 \\
(375.21)\end{array}$ & $\begin{array}{c}0.066 \\
(1.29)\end{array}$ & $\begin{array}{l}0.275^{*} \\
(8.44)\end{array}$ & $\begin{array}{l}-0.209 * \\
(-3.31)\end{array}$ & $\begin{array}{l}1732 \\
(292.27)\end{array}$ & $\begin{array}{c}0.149 \\
(1.18)\end{array}$ & $\begin{array}{c}0.842 * \\
(33.24)\end{array}$ & 47.8 \\
\hline $\begin{array}{l}\text { Precision } \\
\text { machinery }\end{array}$ & $\begin{array}{l}2718 \\
(113.25)\end{array}$ & $\begin{array}{l}0.125 \\
(0.95)\end{array}$ & $\begin{array}{l}0.320 \% \\
(6.99)\end{array}$ & $\begin{array}{l}-0.195 \\
(-1.38)\end{array}$ & $\begin{array}{l}807 \\
(114.57)\end{array}$ & $\begin{array}{l}0.633 * \\
(2.93)\end{array}$ & $\begin{array}{l}0.860 * \\
(21.33)\end{array}$ & 32.5 \\
\hline $\begin{array}{l}\text { Textile } \\
\text { products }\end{array}$ & $\begin{array}{l}5248 \\
(312.20)\end{array}$ & $\begin{array}{l}0.169 * \\
(4.09)\end{array}$ & $\begin{array}{c}0.440 * \\
(14.61)\end{array}$ & $\begin{array}{l}-0.270 * \\
(-4.92)\end{array}$ & $\begin{array}{l}2025 \\
(472.06)\end{array}$ & $\begin{array}{l}0.846 * \\
(19.51)\end{array}$ & $\begin{array}{l}0.849 * \\
(35.26)\end{array}$ & 9.7 \\
\hline $\begin{array}{l}\text { Paper } \\
\text { products }\end{array}$ & $\begin{array}{l}2132 \\
(136.50)\end{array}$ & $\begin{array}{c}0.068 \\
(0.88)\end{array}$ & $\begin{array}{l}0.411 * \\
(9.66)\end{array}$ & $\begin{array}{l}-0.343 * \\
(-3.70)\end{array}$ & $\begin{array}{l}493 \\
(108.37)\end{array}$ & $\begin{array}{l}0.697 * \\
(4.94)\end{array}$ & $\begin{array}{c}0.812 * \\
(14.79)\end{array}$ & 26.0 \\
\hline $\begin{array}{l}\text { Plastics and } \\
\text { products }\end{array}$ & $\begin{array}{l}3671 \\
(151.34)\end{array}$ & $\begin{array}{c}0.082 \\
(1.39)\end{array}$ & $\begin{array}{l}0.302 * \\
(8.05)\end{array}$ & $\begin{array}{l}-0.220 * \\
(-3.06)\end{array}$ & $\begin{array}{l}1064 \\
(196.52)\end{array}$ & $\begin{array}{l}0.414 * \\
(3.67)\end{array}$ & $\begin{array}{c}0.791 * \\
(23.45)\end{array}$ & 12.0 \\
\hline Food & $\begin{array}{l}2426 \\
(154.02)\end{array}$ & $\begin{array}{c}0.064 \\
(0.73)\end{array}$ & $\begin{array}{l}0.149 * \\
(3.10)\end{array}$ & $\begin{array}{l}-0.085 \\
(-0.83)\end{array}$ & $\begin{array}{l}440 \\
(92.78)\end{array}$ & $\begin{array}{l}0.459 * \\
(3.30)\end{array}$ & $\begin{array}{l}0.696 * \\
(12.32)\end{array}$ & 12.8 \\
\hline
\end{tabular}

QN: Number of observations. LRT: Likelihood-ratio chi-square value, degrees of freedom: 8. Below the parameter estimates in parentheses: $t$-values. * indicates significance at least at the $5 \%$ level (one-side test). $\mathrm{DIF}=\gamma(\mathrm{PD})-\gamma(\mathrm{QD})$. C: ten-firm concentration ratio, 1977; source: Monopolkommission, Drittes Hauptgutachten 1978/79, Bundestagsdrucksache $\mathrm{Nr} 8 / 4404,1980$. 